\title{
Knowledge Management and Organizational Performance: A Research On Systematic Literature
}

\author{
Mubarak al Rashdi, Suriati Binti Akmal, Samer Ali Al-shami
}

\begin{abstract}
Studies that investigate the KM and organizational performance are few. The purpose of this study is to review the literature and review the articles related to the effect of knowledge management (KM) on organizational performance. A systematic literature review was conducted, and three screenings were performed to refine the articles. Article were extracted from Scopus and Web of Science (WoS). A total of 29 articles were considered to meet the selection criteria was reviewed, analyzed, and important information was extracted. A frequency analysis was conducted on these articles. The findings indicated that majority of the articles were extracted from WoS and published between 2015-2017 in Malaysia and Taiwan. The reviewed studies were conducted on manufacturing and technological industries using quantitative method. Sample size in most studies is less than 200 and data was analyzed using first generation of data analysis. Findings were discussed, and it was recommended for future studies to increase the sample size and use more frequently structural equation modeling.
\end{abstract}

Keywords- Knowledge Management, Organizational Performance, Systematic Literature review, KM process, KM infrastructure

\section{INTRODUCTION}

Organizational performance is one of the most important variables in the context of management and business studies (Mohamad \& Hoshino, 2012). This is because the organizational performance is an indicator of the level of the economy and can determine to large extent the level of employment, Gross Domestic Product (GDP), and Foreign Direct Investment (FDI)(Ismail, Mohamad, \& Yahya, 2018; Malik, Musa, Ahmad, \& Mohamad, 2014; Shah \& Jan, 2014) A better performance is of extreme importance to stakeholders in general and shareholders in particular, as it helps to increase the value of the business, and offers the basis for distributing dividends, which in turn may attract investors (Müller, 2014).

Majority of previous studies, especially in large scale companies, have linked the performance to internal factors that are collected using secondary data. For this reasons, previous studies are dominated by the secondary data approach, which mainly based on historical financial indicator related to a certain period of time and does not give any indication for future performance of companies (Kaplan \& Norton, 1996). New and emerging variables such as Knowledge Management (KM) have not been

Revised Manuscript Received on April 12, 2019.

Mubarak al Rashdi,Institute of Technology Management and Entrepreneurship, UniversitiTeknikal Malaysia Melaka. (E-mail: alrashdi.mubarak5@gmail.com)

SuriatiBintiAkmal, Institute of Technology Management and Entrepreneurship, UniversitiTeknikal Malaysia Melaka. Entrepreneurship, UniversitiTeknikal Malaysia Melaka.
Samer Ali Al-shami, Institute of Technology Management and

investigated adequately and there is a need to understand the effect of KM practices and capabilities in the context of developing countries(Obeidat et al., 2016; Alaarj, Mohamed and Bustamam, 2017; Bajaj, Garg and Sethi, 2018; Prashar and Antony, 2018).

$\mathrm{KM}$ is considered as a new variable that have been introduced in the last two decades.Several researchers attempt to find the effect of $\mathrm{KM}$ on the organizational outcomes such as competitiveness, innovation, organizational performance, financial performance and nonfinancial performance (Alaarj, Abidin-Mohamed, \& Bustamam, 2016; Fan, Feng, Sun, \& Ou, 2009; Mills \& Smith, 2011). However, there is no agreement between researchers regarding the effect of $\mathrm{KM}$ on organizational performance and researchers have not agreed on the operationalization of KM. For example, Gold et al. (2001) operationalized $\mathrm{KM}$ into $\mathrm{KM}$ process and $\mathrm{KM}$ infrastructure. Where the first includes the process of acquisition, conversion, protection, and application and the latter include the organizational structure, culture, and technology infrastructure. On the other hand, researchers such as Aboyassin et al. (2011) operationalized KM to include diagnosing, acquisition, generation, sharing, storing. For Chang and Chuang (2011), KM is operationalized into choice, access, storage, and sharing.

Few studies reviewed the articles related to $\mathrm{KM}$ and organizational performance. This study aims to review the effect of KM on organizational performance and it also aims to present the state of the art of the research into $\mathrm{KM}$ and organizational performance. The study also aims to provide researchers with direction for future work to enrich the studies in KM and organizational performance. This study consists of six sections. The first section introduced the topic and discussed the issues as well as the objectives. In the next section, the methodology of this study is discussed Third section presents a summary of the reviewed articles. The fourth section presents the findings. In the fifth section, a discussion of the findings is given. Sixth section presents the conclusion, limitations and the direction of future works.

\section{RESEARCH METHODOLOGY}

This study aims to systematically determine the effect of KM on organizational performance. For this reason, a systematic review of the articles that investigate the two topics was conducted. Keywords such as KM, KM process, 
KM infrastructure, knowledge management capability, organizational performance, and a combination of these words were used to identify the articles. Mainly, two databases were used to select the articles. These includes the Scopus and Web of Science (WoS) were used to find the related articles. These databases were selected because they produce only peer-reviewed and reliable articles. A total of 251 articles were identified.

Three screening were conducted to refine the articles. The first screening was to remove the duplicates and none English article as well as the outdated articles before 2007. The 2007 period were taken in this study to review articles published in the last ten years. The first screening resulted in removing 147 articles. In the second screening, the remaining 104 articles were screened in term of titles and abstracts. This has resulted in removing 40 articles based on their relatedness to the topics of this study.

The third screening included a full reading of the 64 articles. In this screening, 35 articles were found not related to the study and thus a decision was made to remove these articles. The 29 remaining articles were reviewed, and their information were extracted. A frequency analysis was conducted on these articles. Figure 1 shows the process of selecting and extracting the articles of this study.

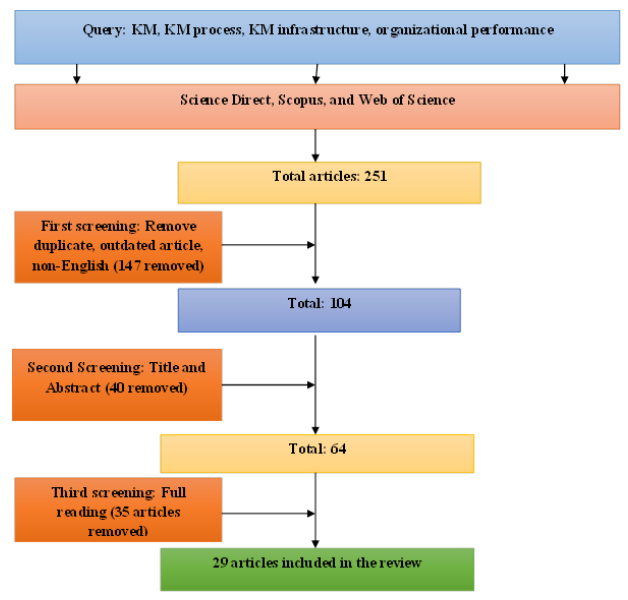

Figure 1: Process of Selecting and Refining the Articles

\section{SUMMARY OF REVIEWED ARTICLES}

A total of 31 articles were reviewed in this study. Boumarafi and Jabnoun (2008) investigated the effect of $\mathrm{KM}$ practices on organizational performance in United Arab Emirates (UAE) and found that KM practices affect the organizational performance. Fan et al. (2009) deployed fuzzy logic to investigate the effect of KM on capabilities and provide a mechanism to evaluate the attribute of KM. Hung, Lien, Fang and McLean (2010) investigated the effect of $\mathrm{KM}$ on innovative performance and found that $\mathrm{KM}$ affected the innovative performance of companies. Chong, Ooi, Lin and Teh (2010)proposes the KM affect the collaborative commerce adoption. Aujirapongpan et al. (2010) reviewed the literature and concluded that $\mathrm{KM}$ is divided into resource based perspective and knowledge based perspective.

Aboyassin et al. (2011) investigated the effect of KM on the total quality management (TQM) and found that KM has essential effect on TQM. Chang and Chuang (2011) established that there is a significant effect between KM and business strategies. In the study of Mills and Smith (2011), the authors concluded that KM affect the organizational performance. Miranda, Lee, and Lee (2011) found that higher investment in KM will lead to better organizational performance. Peng Wong and Yew Wong(2011) and Loke, Downe, Sambasivan and Khalid, (2012) in Malaysia investigated the effect of KM on organizational performance and supply chain learning and found that KM affect significantly the organizational performance and supply chain learning.

$\mathrm{Ng}$ and Jee (2012), Alaaraj, Mohamed and Bustamam (2018); Alaarj, Mohamed and Bustamam (2017b); Alaarj et al. (2017a) investigated the effect of KM on organizational performance of manufacturing and service companies and found significant effect. Siddique (2012) noticed the increased importance of $\mathrm{KM}$ in companies in UAE. Honarpour et al. (2012) linked the KM to the innovation in companies. Stănciuc and Brânzaş (2013) associated between the KM implementation in Europe and the youth growth Valmohammadi and Roshanzamir (2015) and Kahreh et al. (2014) suggested that KM affect the organizational performance and total quality management in pharmaceutical companies and banks in Iran respectively, while Duran et al. (2014) linked it to the total quality service in Turkey. Similarly, in Taiwan and Saudi Arabia, KM was linked to the TQM implementation (Ahmad et al., 2016; Chuang, Chen, \& Tsai, 2015).

Chiu and Chen (2016) investigated in Taiwan the effect of $\mathrm{KM}$ on organizational effectiveness. The finding showed that $\mathrm{KM}$ affect the organizational effectiveness. Honarpour et al. (2017b)Honarpour et al. (2017a) and Yusr et al. (2017) suggested a link between KM and the innovation in Malaysian organizations. In Jordan, Qasrawi et al. (2017) indicated that the effect of $\mathrm{KM}$ on organizational performance is positive and significant. The above is a summary of the reviewed studies. The findings of reviewing the studies are presented in the following studies.

\section{FINDINGS}

The findings of this study are based on frequency analysis conducted after extracting the important information from the 29 articles. The findings are divided into several subsections that cover profile of the articles, publication by year, country, industry, sample size, method, sampling method, and data analysis techniques.

\subsection{Profile of the Articles}

Table 1 presents a profile of the reviewed studies. It shows that third of the articles come from Scopus while two third comes from web of science. Total quality management and business excellence, proceeding of conferences and Journal of knowledge management are the most frequent journals that published the highest number of articles related to $\mathrm{KM}$ and organizational performance. 
Table 1: Profile of the Articles

\begin{tabular}{|l|l|l|}
\hline Indicing & Journal & Frequency \\
\hline Scopus & International Journal of Commerce and Management & 1 \\
\cline { 2 - 3 } & International Journal of Economic Research & 2 \\
\cline { 2 - 3 } & International Review of Management and Marketing & 1 \\
\cline { 2 - 3 } & Conference Proceedings & 4 \\
\cline { 2 - 3 } Science & Journal of Technology Management \& Innovation & 1 \\
\hline \multirow{5}{*}{\begin{tabular}{l} 
Web of \\
\cline { 2 - 2 }
\end{tabular}} & Vine & 1 \\
\cline { 2 - 3 } & Knowledge Management Research \& Practice & 1 \\
\cline { 2 - 3 } & Expert Systems with Applications & 1 \\
\cline { 2 - 3 } & SpringerPlus & 1 \\
\cline { 2 - 3 } & Total Quality Management and Business Excellence & 4 \\
\cline { 2 - 3 } & Expert Systems with Applications & 1 \\
\cline { 2 - 3 } & International Journal of Quality \& Reliability Management & 1 \\
\cline { 2 - 3 } & Journal of Business Economics and Management & 1 \\
\cline { 2 - 3 } & Information \& Management & 1 \\
\cline { 2 - 3 } & Business Process Management Journal & 1 \\
\cline { 2 - 3 } & International Journal of Quality \& Reliability Management & 2 \\
\cline { 2 - 3 } & Journal of Knowledge Management & 3 \\
\cline { 2 - 3 } & International Journal of Production Economics & 1 \\
\hline
\end{tabular}

\subsection{Year of Publications}

Figure 2 shows the year of publications. Few of the articles were published between 2008-2010 while the number increased in 2011-2012. Another increase has been seen between 2016-2018.

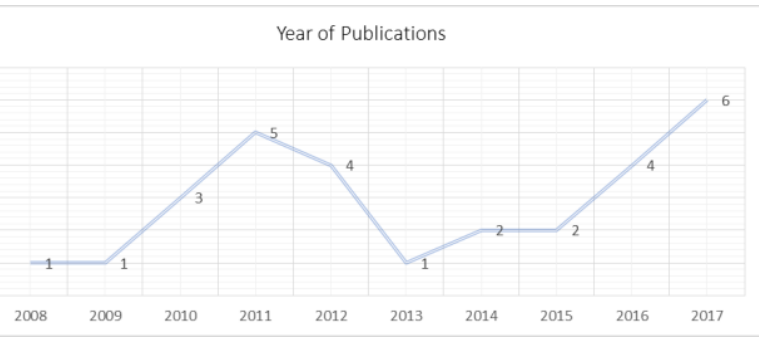

Figure 2: Year of Publications

\subsection{Country of Origin}

Figure 3 shows the country of origin of the studies. A total of $26 \%$ of articles investigated the effect of $\mathrm{KM}$ on organizational performance in Malaysia followed by $16 \%$ in Taiwan, $10 \%$ in Jordan and $13 \%$ has not stated any country due to the fact that these articles either literature review or conceptual articles.

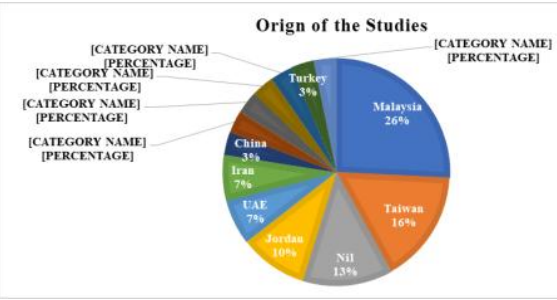

\section{Figure 3: Country of Origin}

Note: Nil: no country

\subsection{Industry}

Figure 4 shows the industries that have been investigated in the reviewed articles. The highest number of articles investigated the manufacturing followed by high tech or technological companies, public listed companies and some researchers stated that their sample includes several industries. Few studies investigated the public sector, services, banks, insurance, and hospital.

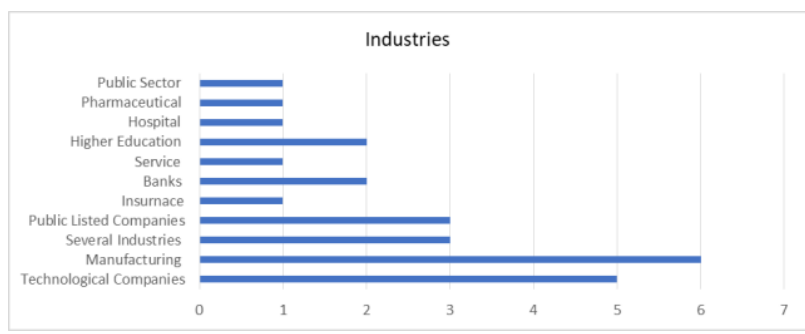

Figure 4: Industries

\subsection{Method}

Figure 5 presents the approach of the reviewed articles. It shows that $79 \%$ of the articles are quantitative followed by $10 \%$ are conceptual articles, $4 \%$ have used mix method and $4 \%$ used qualitative method while only $3 \%$ are literature review articles.

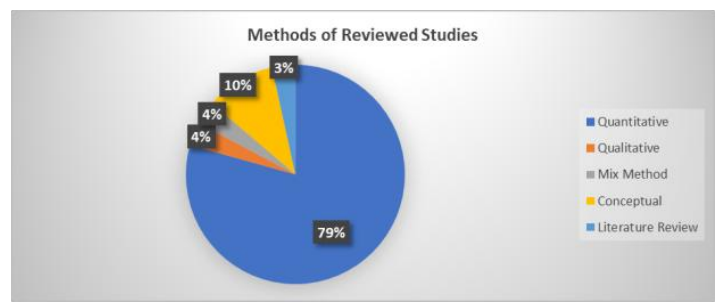

Figure 5: Method of the Reviewed Studies

\subsection{Sample Size}

The sample size of the reviewed articles is presented in Figure 6. It shows that the highest sample size was 470 while the lowest sample size was 62 with overall mean score of sample size 216 respondents. 


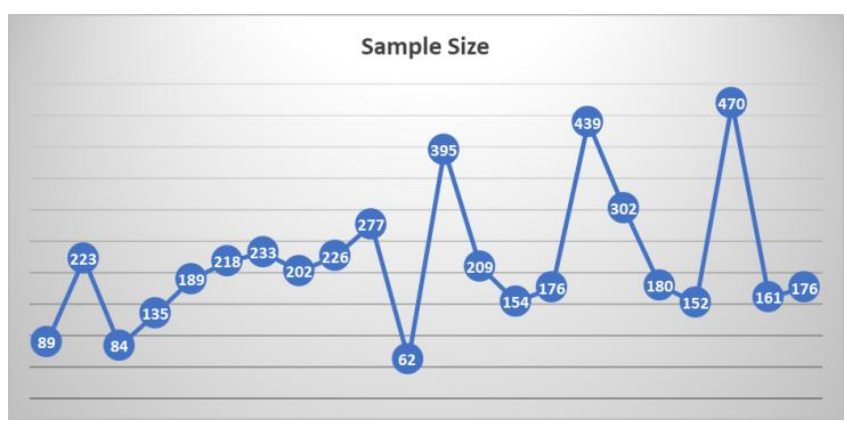

Figure 6: Sample Size

\subsection{Data Analysis Technique}

Figure 6 show the data analysis techniques which was used in the reviewed articles. It can be seen that the highest percentage used Statistical Package for Social Science (SPSS) (40\%) while 24\% deployed Analysis of a Moment Structures (AMOS), $16 \%$ have used Partial Least Square (PLS) and also 16\% have used LISREL. Only 4\% have used fuzzy linguistic.

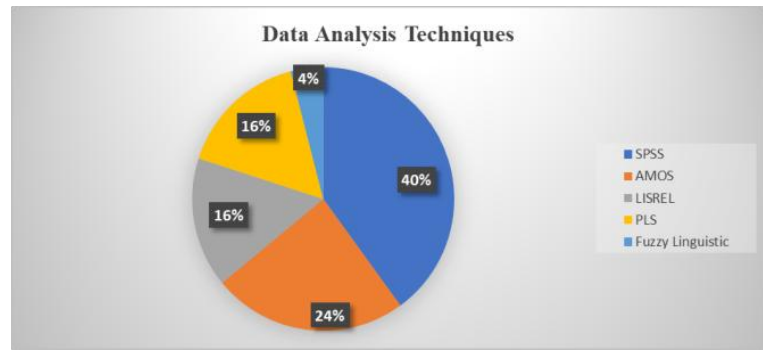

Figure 6: Data Analysis Techniques

\section{DISCUSSION \& RESULTS}

This study was conducted to review the literature of KM and organizational performance. The important points of reviewing the previous studies can be summarized that $\mathrm{KM}$ is important predictors of the organizational performance. Nevertheless, Obeidat et al. (2016) pointed out that few studies focused on KM and its effects on organizational performance. The review of 29 articles agreed with this claim made by Obeidat et al. (2016). Few studies focused on the effect of $\mathrm{KM}$ on organizational performance. The second point is the lack of studies on $\mathrm{KM}$ in developing countries. A metaanalysis study indicated that the majority of articles in peer reviewed journals on KM comes from USA, the UK, Canada, Germany, Australia, and Spain (Serenko, 2013). Alaarj et al. (2016) noted that most of KM studies were conducted in developed countries and in Taiwan. In this study, it was found that articles from Malaysia have overtaken other articles from Taiwan or developed countries. This could be due to the scope of this study where the focus was on the effect of KM on organizational performance. In agreement with previous studies, this study found that some countries have received limited number of articles such as Turkey, China, Iran, and UAE.

The third point is the excessive use of correlational and descriptive analysis rather than the use of cause and effect analysis or regression analysis. In agreement with this point, a previous meta-analysis found that majority of studies between 2002 and 2012 were descriptive research
(Doeleman, ten Have, \& Ahaus, 2014). In the review of 29 articles, it was found that studies were interested in the correlation between KM and organizational performance indicators and dominated by conceptual studies (Boumarafi and Jabnoun, 2008; Aboyassin et al., 2011).

The fourth point that have been observed from previous studies, is the intensive use of SPSS software (Joiner, 2007; Boumarafi and Jabnoun, 2008; Aboyassin et al., 2011; Ng and Jee, 2012; Siddique, 2012; Psomas and Jaca, 2016; Panuwatwanich and Nguyen, 2017; Qasrawi et al., 2017). This is also supported by the fact that more than $40 \%$ of the articles have used SPSS as the data analysis technique rather than the SEM software such as AMOS, PLS, and LISREL.

This was also noted in the study of Khanam, Siddiqui and Talib (2013) who found that SPSS is the most widely software used.

The fifth point is the sample size is limited in most previous studies. It was seen that some studies have used sample size of 62,84 , and 89 . This refers to the limitation of generalizing the findings of these studies and urge for the need of deploying more sample size to generalize the findings. Once again, this supports the need for using the SEM, which typically requires a sample size of 200 (Hair, Hult, Ringle, \& Sarstedt, 2017).

The sixth point is the excessive investigation of manufacturing and technological sectors while other sectors have received less attention. For example, public sector, pharmaceutical, hospital, banks, and higher education. This agrees with Alaarjet a. (2016) who noticed that the majority of previous studies on KM have investigated either the technological or the manufacturing sector.

Lastly, it was noted from previous studies the scarcity of using mediator or moderator to understand the effect of KM practices on organizational performance. This point is supported by the findings of Chuang et al. (2015) who suggested to included mediator or moderator to better understand the effect of $\mathrm{KM}$ on organizational performance. Moderating role of trust and organizational performance was investigated by few researchers and there is a need for more studies to look into the moderating role of these variables. Other variables such as business strategies, and inter-organizational trust as well as the business uncertainty are worthwhile of investigation.

\section{CONCLUSION, LIMITATIONS AND FUTURE WORK}

This study reviewed the literature to present the state of the art in the field of KM and organizational performance. A systematic review was conducted and a total of 29 articles were reviewed, analyzed and important information was extracted. The findings indicated that all the articles were extracted from Scopus and Web of Science with the majority were published between 2015 and 2018. Most of the articles investigated the issue of 
KM and organizational performance in Malaysia, Taiwan, and Jordan. Majority of the studies were conducted on manufacturing and technological industries. The majority of the studies are quantitative with mean of sample size 216. SPSS is the most widely used data analysis techniques followed by AMOS, LISREL and PLS.

The findings of this study are limited to the reviewed articles. Due to the selection criteria of the articles, only 29 articles were reviewed. The findings also are limited to the scope of this study because it focuses on KM and organizational performance. As a way forward, future studies are recommended to expand the scope of this study so that the findings can be more generalizable. Future research is recommended to investigate systematically the literature by including other indices such as to focus only on articles published by Emerald or Science Direct or in specific journal such as the Journal of Knowledge Management. Future studies are recommended to investigate empirically the effect of KM on organizational performance and other organizational outcomes such as competitiveness, innovation, and new product development especially in emerging market. More studies are need in the banking usage of KM to improve the organizational performance. Similarly, more studies are needed in higher education, insurance, hospital, pharmaceutical and more importantly the public sector usage and implementation of KM and organizational.

Future studies are recommended to investigate the KM using methods such as mix method or qualitative studies. Literature review studies are recommended also to determine the direction for future works. Sample size in most studies is less than 200 which does not meet the role of thumb for using AMOS or PLS. Future research is recommended to expand the sample size and use technique such as Structural Equation Modeling (SEM). Using AMOS or PLS should be dependent on the nature of the conducted studies. For this reason, PLS is recommended in explorative nature studies while AMOS for confirmatory studies.

\section{REFERENCES}

1. Aboyassin, N. A., Alnsour, M., \& Alkloub, M. (2011). Achieving total quality management using knowledge management practices. International Journal of Commerce and Management, 21(4), 394-409. https://doi.org/10.1108/10569211111189383

2. Ahmad, A., Ghamdi, A., Shah, F., Abd, B., Yusoff, R. Z., \& Mustafa, M. Bin. (2016). The Moderating Role of Knowledge Management on the Relationship between Employees ' Commitment and Total Quality Management : A Study on the Public Healthcare Sector in Saudi Arabia. International Review of Management and Marketing, 6(4), 4405.

3. Alaaraj, S., Mohamed, Z. A., \& Bustamam, U. S. B. A. (2018). External Growth Strategies and Organizational Performance in Emerging Markets: The Mediating Role of Inter-Organizational Trust. Review of International Business and Strategy, 28(2).

4. Alaarj, S., Abidin-Mohamed, Z., \& Bustamam, U. S. B. A. (2016). Mediating Role of Trust on the Effects of Knowledge Management Capabilities on Organizational Performance. Procedia - Social and Behavioral Sciences, 235, 729-738. https://doi.org/10.1016/j.sbspro.2016.11.074
5. Alaarj, S., Mohamed, Z. A., \& Bustamam, U. S. A (2017a). Do Knowledge Management Capabilities Reduce the Negative effect of Environment Uncertainties on Organizational Performance? A Study of Public Listed Companies in Malaysia. International Journal of Economic Research, 14(15), 443-456.

6. Alaarj, S., Mohamed, Z. A., \& Bustamam, U. S. A. (2017b). The Effect of Knowledge Management Capabilities on Performance of Companies: A Study of Service Sector. International Journal of Economic Research, 14(15), 457-470.

7. Aujirapongpan, S., Vadhanasindhu, P., Chandrachai, A., \& Cooparat, P. (2010). Indicators of knowledge management capability for KM effectiveness. Vine, 40(2), 183-203. https://doi.org/10.1108/03055721011050677

8. Bajaj, S., Garg, R., \& Sethi, M. (2018). Total quality management: a critical literature review using Pareto analysis. International Journal of Productivity and Performance Management, 67(1), 128-154. https://doi.org/10.1108/IJPPM-07-2016-0146

9. Boumarafi, B., \& Jabnoun, N. (2008). Knowledge management and performance in UAE business organizations. Knowledge Management Research \& Practice, 6(3), 233-238. https://doi.org/10.1057/kmrp.2008.16

10. Chiu, C.-N., \& Chen, H.-H. (2016). The study of knowledge management capability and organizational effectiveness in Taiwanese public utility: the mediator role of organizational commitment. SpringerPlus, 5(1), 1520. https://doi.org/10.1186/s40064-016-3173-6

11. Chong, A. Y.-L., Ooi, K.-B., Lin, B., \& Teh, P.-L. (2010) TQM, knowledge management and collaborative commerce adoption: A literature review and research framework. Total Quality Management \& Business Excellence, 21(5), 457-473. https://doi.org/10.1080/14783363.2010.481507

12. Chuang, S. S., Chen, K. S., \& Tsai, M. T. (2015). Exploring the antecedents that influence middle management employees' knowledge-sharing intentions in the context of total quality management implementations. Total Quality Management and Business Excellence, 26(12), https://doi.org/10.1080/14783363.2013.809941

$108-122$.

13. Doeleman, H. J., ten Have, S., \& Ahaus, C. T. B. (2014). Empirical evidence on applying the European Foundation for Quality Management Excellence Model, a literature review. Total Quality Management and Business Excellence, 25(5-6), 439-460 https://doi.org/10.1080/14783363.2013.862916

14. Duran, C., Çetindere, A., \& Şahan, Ö. (2014). An Analysis on the Relationship Between Total Quality Management Practices and Knowledge Management: The Case of Eskişehir. Procedia - Social and Behavioral Sciences, 109, 65-77. https://doi.org/10.1016/j.sbspro.2013.12.422

15. Fan, Z.-P., Feng, B., Sun, Y.-H., \& Ou, W. (2009). Evaluating knowledge management capability of organizations: a fuzzy linguistic method. Expert Systems with Applications, 36(2), 3346-3354. https://doi.org/10.1016/j.eswa.2008.01.052

16. Hair, Hult, T. M., Ringle, C. M., \& Sarstedt, M. (2017). A primer on partial least squares structural equation modeling (2nd ed.). Thousand Oakes.

17. Honarpour, A., Jusoh, A., \& Long, C. S. (2017). Knowledge management and total quality management: a reciprocal relationship. International Journal of Quality \& Reliability Management, 34(1), 91-102. https://doi.org/10.1108/IJQRM-03-2014-0040 
18. Honarpour, A., Jusoh, A., \& Md Nor, K. (2017). Total quality management, knowledge management, and innovation: an empirical study in R\&amp;D units. Total Quality Management \& Business Excellence, 3363(January), $1-19$. https://doi.org/10.1080/14783363.2016.1238760

19. Honarpour, A., Jusoh, A., \& Nor, K. (2012). Knowledge Management, Total Quality Management and Innovation : A New Look. Journal of Technology Management \& Innovation, 7(3), 22-31. https://doi.org/10.4067/S071827242012000300003

20. Hung, R. Y. Y., Lien, B. Y. H., Fang, S. C., \& McLean, G. N. (2010). Knowledge as a facilitator for enhancing innovation performance through total quality management. Total Quality Management and Business Excellence, 21(4), 425-438. https://doi.org/10.1080/14783361003606795

21. Ismail, M., Mohamad, N., \& Yahya, S. (2018). Strategic Orientation and International Firm Performance: A Pilot Study of Malaysian SMEs Halal Product Manufacturer. Advanced Science Letters, 24(4), 2743-2745.

22. Kahreh, Z. S., Shirmohammadi, A., \& Kahreh, M. S. (2014). Explanatory Study Towards Analysis the Relationship between Total Quality Management and Knowledge Management. Procedia - Social and Behavioral Sciences, 109 ,

600-604. https://doi.org/10.1016/j.sbspro.2013.12.513

23. Kaplan, R. S., \& Norton, D. P. (1996). The Balanced Scorecard Translating Strategy In Action (Kaplan \& Norton, 1996, Harvard Business School Press).pdf. Proceedings of the IEEE. https://doi.org/10.1109/JPROC.1997.628729

24. Khanam, S., Siddiqui, J., \& Talib, F. (2013). Role of information technology in total quality management: a literature review. International Journal of Advanced Research in Computer Engineering \& Technology, 2(8), 2433-2445. Retrieved from http://papers.ssrn.com/sol3/papers.cfm?abstract_id=272509 6

25. Loke, S.-P., Downe, A. G., Sambasivan, M., \& Khalid, K. (2012). A structural approach to integrating total quality management and knowledge management with supply chain learning. Journal of Business Economics and Management, 13(4), 776-800. https://doi.org/10.3846/16111699.2011.620170

26. Malik, S. N. A. A., Musa, H., Ahmad, S., \& Mohamad, N. (2014). The Factors Influencing Supply Chain Disruptions on Supply Chain Performance in Small and Medium Enterprises. The Journal of Technology Management and Technopreneurship (JTMT), 2(2).

27. Mills, A. M., \& Smith, T. a. (2011). Knowledge management and organizational performance: a decomposed view. Journal of Knowledge Management, 15(1),

$156-171$. https://doi.org/10.1108/13673271111108756

28. Miranda, S. M., Lee, J.-N., \& Lee, J.-H. (2011). Stocks and flows underlying organizations' knowledge management capability: Synergistic versus contingent complementarities over time. Information \& Management, 48(8), 382-392. https://doi.org/10.1016/j.im.2011.10.002

29. Mohamad, N., \& Hoshino, Y. (2012). Survival and financial performance of Japanese subsidiaries in Malaysia and Thailand. Business and Management Review, 2(4), 21-41.

30. Müller, V.-O. (2014). Do Corporate Board Compensation Characteristics Influence the Financial Performance of Listed Companies? Procedia - Social and Behavioral Sciences, 109 983-988. https://doi.org/10.1016/j.sbspro.2013.12.575

31. Ng, P. K., \& Jee, K. S. (2012). Innovating TQM, CE and $\mathrm{KM}$ for productive manufacturing in a Malaysian firm.
Total Quality Management and Business Excellence, 23(910), https://doi.org/10.1080/14783363.2012.704283 $1089-1105$

32. Obeidat, B. Y., Hashem, L., Alansari, I., Tarhini, A., \& AlSalti, Z. (2016). The Effect of Knowledge Management Uses on Total Quality Management Practices: A Theoretical Perspective. Journal of Management and Strategy, 7(4), 18-29. https://doi.org/10.5430/jms.v7n4p18

33. Peng Wong, W., \& Yew Wong, K. (2011). Supply chain management, knowledge management capability, and their linkages towards firm performance. Business Process Management Journal, 17(6), 940-964. https://doi.org/10.1108/14637151111182701

34. Qasrawi, B. T., Almahamid, S. M., \& Qasrawi, S. T. (2017). The impact of TQM practices and KM processes on organisational performance. International Journal of Quality \& Reliability Management, 34(7), 1034-1055. https://doi.org/10.1108/IJQRM-11-2015-0160

35. Serenko, A. (2013). Meta-analysis of scientometric research of knowledge management: discovering the identity of the discipline. Journal of Knowledge Management, 17(5), 773-812. https://doi.org/10.1108/JKM-05-2013-0166

36. Shah, S. Q., \& Jan, R. (2014). Analysis of Financial Performance of Private Banks in Pakistan. Procedia Social and Behavioral Sciences, 109, 1021-1025. https://doi.org/10.1016/j.sbspro.2013.12.583

37. Siddique, C. M. (2012). Knowledge management initiatives in the United Arab Emirates: a baseline study. Journal of Knowledge Management, 16(5), 702-723. https://doi.org/10.1108/13673271211262763

38. Stănciuc, A. M., \& Brânzaş, B. V. (2013). Knowledge management and total quality management integration: impact on national youth strategy, 557-564.

39. Valmohammadi, C., \& Roshanzamir, S. (2015). The guidelines of improvement: Relations among organizational culture, TQM and performance. International Journal of Production Economics, 164, 167178. https://doi.org/10.1016/j.ijpe.2014.12.028

40. Yusr, M. M., Mokhtar, S. S. M., Othman, A. R., \& Sulaiman, Y. (2017). Does interaction between TQM practices and knowledge management processes enhance the innovation performance? International Journal of Quality \& Reliability Management, 34(7), 955-974. 